\title{
A Study on Laboratory Rearing of Lady Bird Beetle (Coccinella Septempunctata) to Observe Its Fecundity and Longevity on Natural and Artificial Diets
}

\author{
Muhammad Ashraf \\ University College of Agriculture, Rawalakot, Azad Jammu and Kashmir, Pakistan \\ Tel: 92-582-296-0431 E-mail: chashraf_horti@hotmail.com
}

Muhammad Ishtiaq (Corresponding author)

Department of Botany, University of Azad Jammu and Kashmir, Muzaffarabad (AK), Pakistan

Department of Botany, Mirpur University of Science \& Technology (MUST)

Bhimber Campus, Azad Jammu and Kashmir, Pakistan

Tel: 92-582-296-0431Ｅ-mail: drishtiaqajk@gmail.com,drishtiaq@ajku.edu.pk

Muhammad Asif, Muhammad Adrees \& Muhammad Nauman Ayub

University College of Agriculture, Rawalakot, Azad Jammu and Kashmir, Pakistan

Tel: 92-582-296-0431

Tariq Mehmood

Department of Botany, University of Azad Jammu and Kashmir, Muzaffarabad (AK), Pakistan

Tel: 92-582-296-0431

Muhammad Naeem Awan

Department of Wildlife, Ministry of Environment Muzaffarabad, Azad Jammu and Kashmir, Pakistan

E-mail: ajkwildlife@gmail.com

\begin{abstract}
Development and reproductive potential of the Coccinella septempunctata L. (CSL) was conducted under laboratory conditions to determine its fecundity and longevity on natural and artificial diets. Tests were made on laboratory rearing materials and all development stages were carefully recorded. Success ratios in these experiments were a matter of logistic and synchronization of these life cycles, the plant phytophagous and entomophagous insects. A positive correlation was obtained between food consumption and egg production, so fecundity of CSL is affected by the type of food. CSL consumed highly significant (Rhopalosiphum maidis) 32.2 aphids per day as compared to other treatments. Oviposition response was the maximum on these beetles which consumed $1^{\text {st }}$ and $2^{\text {nd }}$ instars of Macrosiphon roseae. CSL reared under artificial diet showed more longevity 41.6 days on plain water. Greater emphasis was pertinent on evaluation of predator specificity, understanding of colonization in new environments and assessment of community-level interactions to maximize the use of Coccinellids in Biological Control (BC).
\end{abstract}

Keywords: Coccinella septempunctata, Mass rearing, Fecundity, Longevity, Biological control

\section{Introduction}

Different types of pests are found in nature affecting life and yield of natural and cultivated crops of agro-forestry. 
They hamper and destroy standing and stored foods reserves in every part of world (Kring, 1998). Scientists are trying to develop and apply different techniques to control and reduce loss of these pests on agriculture, forest and garden products. Chemical Control Method (CCM) is frequently applied as it is easy and prompt way to directly kill or repel the pests from crops and fruit tree (Katsarou, 2005). But it is reported in many experiments that CCM has not only hazardous effects on human life by increasing pollution but also it has indirect impact by disturbing ecosystems. Recently, it is reported that Biological Control Method (BCM) is better technique to control the pest of different types (Habeck, 1990).

In many studies it is known that Coccinella septempunctata L. (CSL) commonly called Lady bird beetle is a capable predator and can be used for the biological control of T. tabaci and T. vaporariorum in a greenhouse (Solomon, 1949). In an extensive survey of District Poonch of Azad Jammu and Kashmir, it was demonstrated there are 13 species Coccinella septempunctata which belong to subfamily Coccinellinae (Inya, 2005). It is demonstrated in previous studies that CSL responds to olfactory cues from their aphid prey and can even distinguish between aphid species on volatiles (Sengonca, 1994). CSL is considered to be an important bio-control agent for soft-bodied insects such as aphids, white flies, jassids and small lepidopterous larvae which were among the first to be used in this fashion (Victor, 1997). Deligeorgidis has also reported in his findings that CSL can prove to be a good bio-control source for thrips and whiteflies in green house crops also (Deligeorgidis, 2005).

The CSL larva gains size from 1 to 4-7mm in 10-30 days time span depending on food availability. It has two generations before onset of winter and hibernation activity (Katsarou, 2005). inhabits a wide variety of environments and mass rearing method of aphid predators has been considered as one of the most important conditions for the realization of their control potential (Mackauer, 1976). The life cycle of CSL is ranging from 19-24 days depending on prey species they feed. The insect predator may commit to reproduction to varying degree depending of the nature of the prey they consume (Evans, 2004). To be successful, the CSL searching strategy pre-supposes a high capacity to meet variation in food, plus a capacity for learning as suggested by Vet Lem (1992). Hodek discussed the potential advantages for some ladybird species with mixed feeding i.e. a diet that contains aphids as well as pollen (Hodek, 1996). A valuable contribution on habituation of CSL to one aphid species proved to diminish the capacity to use another species as optimal food (Rana, 2002). It is known that fecundity of CSL is also affected by the quality of food eaten, so there is a positive correlation between food consumption and egg production (Ibrahim, 1955). But no work is conducted on quantitative assessments of the efficacy of Coccinellids have not been done for most species in most agricultural crops. In this study, it was objected to find the relation of CSL with different types of food and how it affects the longevity and fecundity. Furthermore, it was also an aim to explore the food and environment correlation for population density and life span of CSL and its importance as BCM as environment friendly technique.

\section{Materials and methods}

The present study was conducted in Entomological laboratory $\left(28^{\circ} \mathrm{C}, 65 \% \mathrm{RH}\right.$ and $\left.14 \mathrm{D}: 10 \mathrm{~L}\right)$ at University College of Agriculture, Rawalakot, Azad Kashmir, Pakistan during the year 2003. The materials used and methods applied in the study are given below.

\subsection{Materials}

During the experiment following materials were used:

$\begin{array}{ll}\text { 1. } & \text { Rearing Cages } \\ \text { 3. } & \text { Beakers } \\ \text { 5. } & \text { Plain water } \\ \text { 7. } & \text { Honey syrup } \\ \text { 9. } & \text { Filter papers }\end{array}$

2. Disposable Petri dishes

Initially field collected adults of CSL were reared in laboratory and later on all developmental stages were reared and kept under study. Three aphid prey species (Bravicoryne brassicae, Macrosiphon roseae and Rhopalosiphum maidis) were also reared within cages for feeding of CSL. They were maintained all the time on Cabbage seedlings, Rose plants and Maize plants. All the four instars were tested for feeding.

\subsection{Methods}

Adults of CSL were collected from the agriculture fields and reared in Entomology laboratory. The field-collected material was sorted out in the laboratory and pairs were selected for oviposition. The selected pairs were kept in separate petri dishes to get the batches of eggs for single cohort offspring to minimize the variation in the experiments. Then beetles were reared on aphids. The experiment was carried out in the laboratory under homogeneous condition. The experiment was laid out according to Complete Randomized Design (CRD) with 
three replications and eight treatments. The treatments means were analyzed using analysis of variance (ANOVA).

\section{Natural diet}

$\mathrm{T} 1$

$\mathrm{T} 2$

T3

$\mathrm{T} 4$

T5

\section{Artificial diet}

$\mathrm{T} 1$

$\mathrm{T} 2$

T3

\author{
Brevicoryne brassicae \\ $1^{\text {st }}$ and $2^{\text {nd }}$ instars of Macrosiphon roseae \\ Alete of Macrosiphon roseae \\ Rhopalosiphum maidis \\ Rhopalosiphum maidis on filter paper surface
}

The variables under study were fecundity and longevity. The fecundity of CSL was checked and data were recorded daily. In this experiment a copulating pairs were selected and put in petri dishes for mating purpose and then to get the batches of eggs. During experiment following observations were recorded.

Number of aphids consumed by each predator pair per day/Total number of eggs laid by each predator pair during the experiment

To determine the longevity of the predator, the adults were fed with honey syrup, sugar syrup and plain water alone. Three replications of each were tested. The number alive or dead was recorded daily.

\section{Longevity on Honey Syrup}

The Honey syrup was given to CSL with the help of cotton boll every day to observe the longevity and data was recorded daily.

\section{Longevity on Sugar Syrup}

Daily Sugar syrup was given to CSL in cotton boll to check the longevity on Sugar syrup, and data was recorded.

\section{Longevity on Water}

The boiling water in cotton boll was also given to CSL to observe the longevity and data was recorded daily.

\section{Results and discussion}

Keeping in view the role of this predator, the present study was initiated by considering two paramount features of this particular predator. The population of the predator was at higher level during the month of March - April. Meanwhile, the population of aphids is also at higher level during this period. Under field conditions, the activity of both predator and the prey is quiet visible. The data obtained from comparative feeding behavior of CSL was collected and formulated in the tabular form. The prey-predator interaction of each day was calculated and their data are presented in Table 1. This correlation of prey-predator is analyzed statistically using ANOVA and DMR test represented by Table 1.1 and 1.2, respectively.

The Table 1.1 indicates a highly significant consumption by CSL on treatment T4 (Rhopalosiphum maidis) with (32.21 aphids/day) compared to very low consumption by predators on treatment T1 (Brevicoryne brassicae), T2 (Brevicoryne brassicae) and treatment T3 (Alete of Macrosiphon roseae) with (18.39 and 10.57) aphids/day, respectively as indicated in Fig.1. It is because of the Brevicoryne brassicae covered with powdery material which was not palatable for CSL which supports previous findings of Jonathan (Jonathan, 2005). However, in present study prey consumption by CSL on treatment T1 (Brevicoryne brassicae) was in agreement to that of peach aphids (Phyllaphus fagi) which cover their bodies and surround their colony with a white flaky material. This may inconvenience to predators by making individuals prey selection as difficult for feeding. It was found during the study that treatment T3 (Alete of Macrosiphon roseae) has taken less number of aphids 10.57 aphids/day by predators because it was fully wing developed and skin of the aphid was very hard, so the Coccinellids were reluctant to eat. Whereas, the consumption recorded on treatment T5 (Rhopalosiphum maidis on filter paper) and treatment T2 $\left(1^{\text {st }}\right.$ and $2^{\text {nd }}$ instars of Macrosiphon roseae) was (24.50 and 18.39) aphids, respectively. The consumption by CSL on treatment T5 was also higher as compared to other treatments like T1, T2 and T3. It was due to the rough surface of filter paper in petri dish or due to roughness the predator moved quickly and prey-capturing speed was fast. But it is seen that CSL eagerly feed on Rhopalosiphum maidis that might be its favourite diet and captures it more conveniently (Smith, 1965; 1966).

The Table 2 shows significant correlation between egg laying of CSL and food consuming the treatment T2 $\left(1^{\text {st }}\right.$ 
and $2^{\text {nd }}$ instars of Macrosiphon roseae), (17.33 eggs) as compared to other treatments T1, T3, T4 and T5 (Fig.2). It may be due to temperature factor (Katsarou 2005). The temperature also affects the oviposition rate and fecundity as shown in Fig. 2 (Singh and Sing, 1994). The results obtained in Table 2.1 were similar with that maximum oviposition rate was attained at $32^{\circ} \mathrm{C}$ and fecundity was highest at $30^{\circ} \mathrm{C}$ but fecundity was low at $26^{\circ} \mathrm{C}$ and $34^{\circ} \mathrm{C}$ (Fig. 2). The present study was conducted at $26^{\circ} \mathrm{C}$ in the Entomological laboratory. So, the temperature may also affect the fecundity (Hemptinne, 2001). Another factor which influences the fecundity was over wintering of predator (Katsarou, 2005). Lack of food and relatively low temperature is unsuitable for high level of activity. Most species start over winter in September and October. Fecundity is also affected by the quantity of food eaten, so there is positive correlation between food consumption and egg production (Ibrahim, 1955). Similarly, it was reported that Menochilus sexmaculatus did not reproduce when aphid's number was less or low than 29 aphids.

The results obtained about fecundity are shown in Table 2.1 which are in contrast with previous studies (Rajamohan, 1973; Rajamohan, 1974). In their research it was reported that Menochilus sexmaculatus had the highest fecundity when reared on Ahpis craccivora (1107 eggs), followed by Aphis gossypii (718 eggs), Rhopalosiphum maidis (522 eggs) and Aphis umbrella (276 eggs), respectively. The results of this study prove that difference in egg lying of CSL is due to temperature fluctuation (Katsarou, 2005). Other factors such as feeding behavior and climatic or lab environment variations may also affect the life cycle of CSL; more detailed and comprehensive studies are suggested to unravel this plethora.

The predator in Table 3.1 showed significantly higher longevity on treatment T3 (Plain water), (41.67 days) as compared to very low longevity recorded on treatment T1 (honey), (27.67 days) as depicted Fig.3, because in natural water is only major source for survival of insects which is present ever where, so the beetles could prolong its life on water when there is no other food available. Whereas the longevity recorded on treatment T2 (sugar syrup) was 36.00 days. However, the present study with regard to longevity on water and sugar syrup was in agreement to those of (Samalo, 1976) that M. sexmaculatus adult could live for 28 days on sugar syrup and water alone. The present study was carried out at $28^{\circ} \mathrm{C}$ in the Entomological laboratory. So, the difference in finding in days of longevity was due to temperature.

Findings of this experiment predict that there is a profound reliability among various parameters such as food type and temperature; which affect the relationship among predators (CLS) or preys i.e. aphids and other insects (Zarpas, 2005). The life form study of CSL and aphids in different climates can lead us to discover the ways and means to overcome the damages caused by different insects to of various crops that is congruently favouring the biocontrol mechanism (Bierne,1962; Greathead). So, this technique can be used as bio-control technique for avoiding loss in yield of various cash crops and this is also studied in past years (Yamamura \& Yano, 1988). It is better to use organisms of kind to suppress the control the other harmful or crop destroying pests or insects which will be environment friendly without interrupting natural chain and setup of ecosystems (Gautam, 1994). This will be not only a boosting step for our economy by enhancing per hectare yield but also cost effect and affordable method for layman and farmers at broad level.

\section{Concluding perspectives}

It is recommended by analyzing the experimental results that CSL growth rate population size is affected by type of food and temperature. Further more, fecundity and longevity parameters have coincidence with egg lying capacity of CSL and is directly affected by type diet available. When CSL consumed prey Rhopalosiphum maidis then it was predicted that there was a significant increment in its population. CSL demonstrated more yield on artificial diet than on plain water. Finally, it is conclude that knowing the all behavioral style of CSL can be helpful in enhancing its population in lab and it can be applied in fields for pest control as technique of BCM.

\section{References}

Bierne, B. (1962). Trends in applied biological control of insects. Ann. Rev. Ent., 7: 387-400.

Deligeorgidis, P. N., I., M. Vaiopoulou, G. Kaltsoudas and G. Sidiropoulos. (2005). Predatory effect of Coccinella septempunctata on Thrips tabaci and Trialeurodes vaporariorum, JEN 129(5): 246-249. doi: $10.1111 / \mathrm{j} .1439-0418.2005 .00959 .246-249$.

Evans, E. W. (2004). Egg production in response to combined alternative foods by the predator Coccinella transversalis. Entomologia, Experiments at Applicata, 34(2): 141-147.

Gautam, R. D. (1994). Biological Pest Suppression. Westvill Publishing House, New Delhi. pp 219.

Greathead, D. J. (1986). Parasitoids in classical biological control. p. 289-318.

Greathead D. J. (eds.), Insect Parasitoids. 13th Symp. of the Royal Ent. Soc. of London. Academic Press, London.

Habeck, D.H., Bennett, F.D., and Frank, J.H. (1990). Classical Biological Control in the Southern United States. Southern Cooperative Series Bulletin No. 355, IFAS Editorial, University of Florida, Gainesville, FL. pp 197. 
Hemptinne, G. L., M. Doumbia, A. F. G. Dixon. (2001). "Chemical nature and persistence of the oviposition deterring pheromone in the tracks of the larvae of the two spot ladybird, Adalia bipunctata (Coleoptera: Coccinellidae), $J$. Chemoecology, 11: 43-47.

Hodek I. H. A. (1996). Ecology of Coccinellidae. Kluwer Academic Publishers, Dordrecht.

Ibrahim, M. M. (1955). Studies on Coccinella undecimpunctata. aegyptiae Reiche. I. Preliminary notes and morphology of the early stages. Bulletin of the Society of Entomologist Egypt, 39: 251-274.

Inayatullah, M., Hayat, A., Rafi, M.A. (2005). Species composition, distribution and seasonal occurrence of Coccinellidae (Coleoptera) in district Poonch, Azad Kashmir, Pakistan, with new records. Sarhad Journal of Agriculture (Pakistan). 21(1) p. 97-100.

Jonathan, G. Lundgren, R. N. (2005). Wiedenmann Tritrophic Interactions Among Bt (Cry3Bb1) Corn, Aphid Prey, and the Predator Coleomegilla maculata (Coleoptera: Coccinellidae). Environmental EntomologyArticle, 1621-1625.

Katsarou, I., Margaritopoulos, J. T., Tsitsipis, J. A., Perdikis, D. C., Zarpas, K. D. (2005). Effect of temperature on development, growth and feeding of Coccinella septempunctata and Hippodamia convergens reared on the tobacco aphid, Myzus persicae nicotianae. BioControl, 50 (.4): 565-588.

Kring, J. J. O. T. J. (1998). Predaceous Coccinellidae in Biological Control. Annual Review of Entomology, 43: 295-321.

Mackauer, M. a. W., M.J. (1976). Myzus persicae Sulz., an Aphid of World Importance (Chapter:Predator) In:V.L. Delucchi (Editor). Studies in Biological Control, IBP9, Cambridge University Press. 51 (119): 100-104.

Singh, H. S. and Singh R. (1994). Life fecundity table of Coccinella septempunctata Linn. predation on mustard aphid (Lipaphis erysimi Kalt.) under laboratory and field conditions. J. Entomol. Res., 18, 297-303.

Rajamohan, N. A. S. J. (1973). Studies on the Reproduction of Coccinellid Menochilus sexmaculatus (F.) on four species of Aphids. Zeitschrift fur Angewandte Entomologie, 74(4): 388-393.

Rajamohan, N. A. S. J. (1974). Growth and Development of the Coccinellid Menochilus sexmaculatus Fabricus on four species of Aphids. Madras Agricultural Journal, 61(5): 118-122.

Rana, J. S., D. A., Jarosik V. (2002). Costs and benefits of prey specialization in a generalist insect predator. J. Anim. Ecol., 71: 15-22.

Samalo, A. P. a. M. P. (1976). Effect of Various Food Substances on Longevity and Fecundity of some Ladybird Beetles. Indian J. of Entomol., 39(2): 190-192.

Sengonca C, L. B. Z. (1994). Responses of the different instar predator, Coccinella septempunctata L. (Coleoptera: Coccinellidae), to the kairomone produced by the prey and non-prey insects as well as the predator itself. Pflanzenk Pflanzen, (101): 173-177.

Smith, B. C. (1965). Growth and development of coccinellid larvae on dry foods (Coleoptera: Coccinellidae). Canad. Ent., 97: 760-68.

Smith, B. C. (1966). Effect of food on some aphidophagous Coccinellidae. p. 75-81. In: I. Hodek (ed.), Ecology of Aphidophagous Insects. Academia Publ. House, Czechoslovak Acad. Sci., Prague.

Solomon, M. E. (1949). The natural control of animal populations. Journal of Animal Ecology, 18: 1-35.

Srivastava S. (2000). Certain aspects of bioecology and ethology of a ladybeetle Coccinella septempunctata Linnaeus (Coccinellidae: Coleoptera). PhD Thesis. University of Lucknow, Lucknow. pp 160.

Vet Lem, D. M. (1992). Ecology of infochemical use by natural enemies in a tritrophic context. Ann. Rev.Entom., 37: 141-172.

Victor, N. K. (1997). Lady Beetles of the Russian Far East. Center For Systematic Entomology. Memoir 1: 4-5.

Yamamura, N. \& E. Yano. (1988). A simple model of host-parasitoid interaction with host-feeding. Res. Popul. Ecol., 30: 353-69. 
Table 1. Number of aphids consumed by CSL/day

\begin{tabular}{|l|l|l|l|}
\hline Treatments & R1 & R2 & R3 \\
\hline T1 & 6.08 & 8.00 & 7.83 \\
\hline T2 & 22.16 & 16.5 & 16.5 \\
\hline T3 & 12.14 & 10.28 & 9.28 \\
\hline T4 & 32.00 & 32.8 & 31.83 \\
\hline T5 & 23.00 & 24.75 & 25.75 \\
\hline
\end{tabular}

Table 1.1 ANOVA for Number of aphids consumed by CSL/day

\begin{tabular}{|l|l|l|l|l|l|}
\hline S.O.V & D.F & S.S & M.S & F-value & Prob. \\
\hline Between & 4 & 1236.710 & 309.177 & $95.896^{* *}$ & 0.032 \\
Within & 10 & 32.241 & 3.224 & & \\
Total & 14 & 1268.91 & & & \\
\hline
\end{tabular}

If Prob. $<0.05$, it is significant and if Prob. $<0.0001$, it is highly significant; "DMR" test is presented below in Table 1.2 for comparison of their means.

Table 1.2 Means of aphid consumption of CSL/day

\begin{tabular}{|lcc|lll|}
\hline \multicolumn{2}{|l|}{ Original order } & & \multicolumn{3}{l|}{ Ranked order } \\
\hline T1 & 7.303 & E & T4 & 32.21 & A \\
T2 & 18.39 & C & T5 & 24.50 & B \\
T3 & 10.57 & D & T2 & 18.39 & C \\
T4 & 32.21 & A & T3 & 10.57 & D \\
T5 & 24.50 & B & T1 & 7.303 & E \\
\hline
\end{tabular}

T1

$\mathrm{T} 2$

T3

T4

T5
Brevicoryne brassicae

$1^{\text {st }}$ and $2^{\text {nd }}$ instars of Macrosiphon roseae

Alete of Macrosiphon roseae

Rhopalosiphum maidis

Rhopalosiphum maidis on filter paper surface 
Table 2. Egg laying capacity of CSL on different treatments

\begin{tabular}{|c|c|c|c|}
\hline Treatments & R1 & $\mathbf{R 2}$ & R3 \\
\hline $\mathrm{T} 1$ & - & - & - \\
\hline $\mathrm{T} 2$ & 14 & 5 & 33 \\
\hline T3 & - & - & - \\
\hline $\mathrm{T} 4$ & - & - & - \\
\hline T5 & - & - & - \\
\hline
\end{tabular}

T1

$\mathrm{T} 2$

T3

T4

T5
Brevicoryne brassicae

$1^{\text {st }}$ and $2^{\text {nd }}$ instars of Macrosiphon roseae

Alete of Macrosiphon roseae

Rhopalosiphum maidis

Rhopalosiphum maidis on filter paper surface

Table 2.1 ANOVA for oviposition response of CSL

\begin{tabular}{|l|l|l|l|l|l|}
\hline S.O.V & D.F & S.S & M.S & F-value & Prob. \\
\hline Between & 4 & 721.067 & 180.267 & $4.411^{*}$ & 0.0260 \\
Within & 10 & 408.667 & 40.867 & & \\
Total & 14 & 1129.733 & & & \\
\hline
\end{tabular}

If Prob. $<0.05$, it is significant and if Prob. $<0.0001$, it is highly significant and "DMR" test was conducted and presented below in Table 2.2 for comparison of their means.

Table: 2.2 Means of oviposition response of CSL

\begin{tabular}{|lcc|ccc|}
\hline \multicolumn{2}{|l|}{ Original Order } & & \multicolumn{3}{|l|}{ Ranked Order } \\
\hline T1 & 0.0000 & B & T2 & 17.33 & A \\
\hline $\begin{array}{l}\text { T2 } \\
\text { A }\end{array}$ & & 17.33 & T1 & 0.0000 & B \\
\hline T3 & 0.0000 & B & T3 & 0.0000 & B \\
\hline T4 & 0.0000 & B & T4 & 0.0000 & B \\
\hline T5 & 0.0000 & B & T5 & 0.0000 & B \\
\hline
\end{tabular}

T1

$\mathrm{T} 2$

T3

T4

T5

\section{Brevicoryne brassicae}

$1^{\text {st }}$ and $2^{\text {nd }}$ instars of Macrosiphon roseae

Alete of Macrosiphon roseae

Rhopalosiphum maidis

Rhopalosiphum maidis on filter paper surface 
Table 3. Longevity of adult CS L on different treatments

T1

$\mathrm{T} 2$

$\mathrm{T} 3$

\begin{tabular}{|l|l|l|l|}
\hline Treatments & R1 & R2 & R3 \\
\hline T1 & 34 & 25 & 24 \\
\hline T2 & 33 & 35 & 40 \\
\hline T3 & 39 & 40 & 46 \\
\hline
\end{tabular}

\section{Honey syrup}

Sugar syrup

Plain water

Table 3.1 ANOVA for Longevity of adult CSL

\begin{tabular}{|l|l|l|l|l|l|}
\hline S.O.V & D.F & S.S & M.S & F-Value & Prob. \\
\hline Between & 2 & 297.556 & 148.778 & $7.740^{*}$ & 0.0218 \\
Within & 6 & 115.333 & 19.222 & & \\
Total & 8 & 412.889 & & & \\
\hline
\end{tabular}

If Prob. $<0.05$, it is significant and Prob. $<0.0001$, it is highly significant and "DMR" test was used to compare means as in presented below in Table 2.2.

Table 3.2 Means of longevity of adult CSL

\begin{tabular}{|lll|lll|}
\hline \multicolumn{3}{|c|}{ Original order } & & \multicolumn{3}{|c|}{ Ranked order } \\
\hline T1 & 27.67 & B & T3 & 41.67 & A \\
\hline T2 & 36.00 & AB & T2 & 36.00 & AB \\
\hline T3 & 41.67 & A & T1 & 27.67 & B \\
\hline
\end{tabular}

T1

$\mathrm{T} 2$

$\mathrm{T} 3$
Honey syrup

Sugar syrup

Plain water

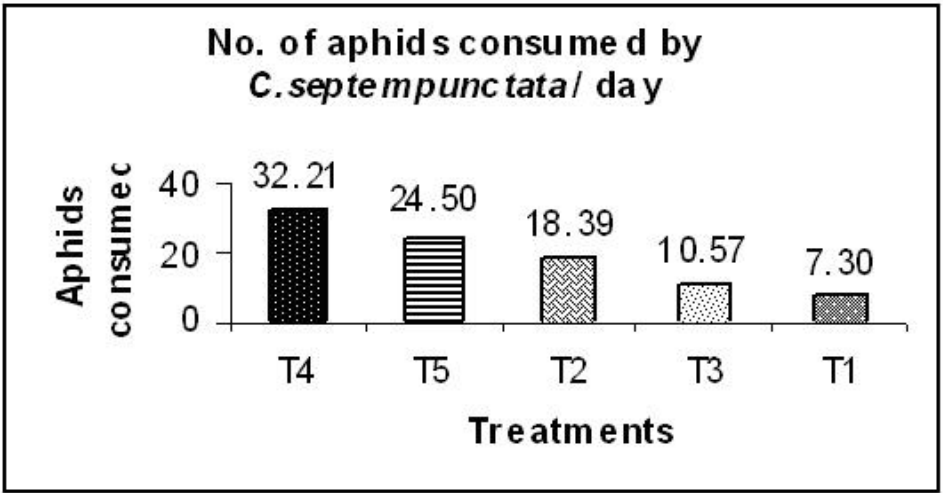

Figure 1. Showing number of aphids consumed by adult CSL/day

Brevicoryne brassicae

$1^{\text {st }}$ and $2^{\text {nd }}$ instars of Macrosiphon roseae

Alete of Macrosiphon roseae 


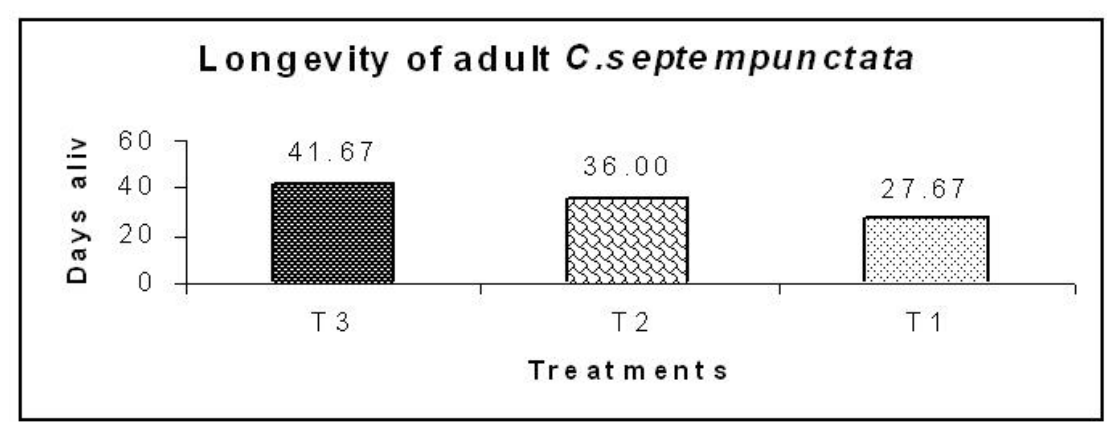

Figure 2. Showing oviposition response of adult CSL on different treatments

$\mathrm{T} 1$

$\mathrm{T} 2$

$\mathrm{T} 3$

$\mathrm{T} 4$

$\mathrm{T} 5$
Brevicoryne brassicae

$1^{\text {st }}$ and $2^{\text {nd }}$ instars of Macrosiphon roseae

Alete of Macrosiphon roseae

Rhopalosiphum maidis

Rhopalosiphum maidis on filter paper surface

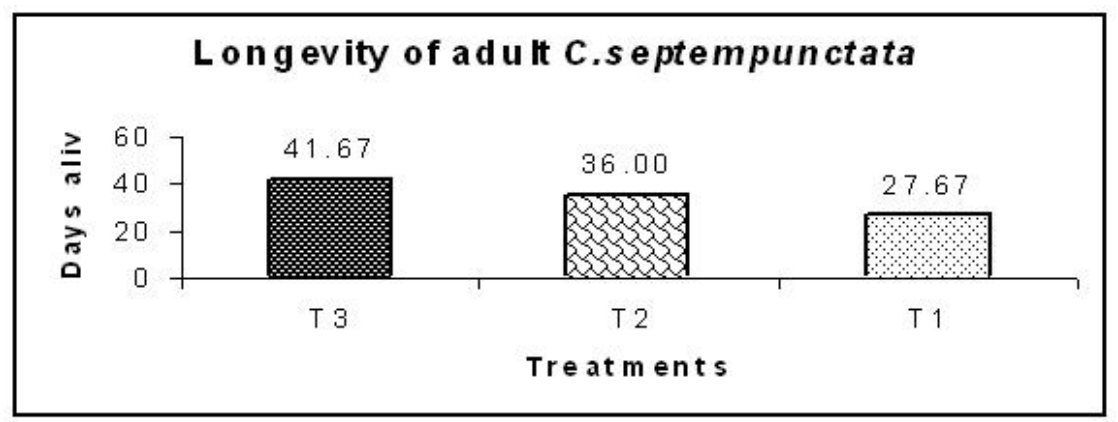

Figure 3. Showing longevity of adult CSL on different treatments

$\mathrm{T} 1$

$\mathrm{T} 2$

$\mathrm{T} 3$
Honey syrup

Sugar syrup

Plain water 